\title{
ALGUMAS CONSIDERAÇÕES SOBRE O SUJEITO NA PSICOSE
}

Gabriela Rinaldi Meyer

Psicanalista;

Mestre em Teoria Psicanalítica pela UFRJ; Doutora em Psicologia Clínica pela USP; Psicóloga do CAPS Clarice Lispector.
RESUMO: Faz-se uma reflexão sobre a questão do sujeito na psicose, sustentando a hipótese da presença de sujeito nesta estrutura. É a partir da fala e do modo como esta é endereçada ao outro na clínica que podemos escutar e identificar o sujeito. Na medida que o sujeito é falante, sua relação com o outro não se fecha numa relação dual, já que inclui um terceiro, o grande Outro. É esta relação que nos oferece o caminho para investigar o que é específico do sujeito na psicose, o que é trabalhado por meio da análise de um fragmento clínico.

Palavras-chave: Sujeito, psicose, linguagem, clínica.

ABSTRACT: Remarks regarding the issue of the subject in psychosis. This article reflects on the issue of the subject in psychosis and supports the hypothesis that the subject exists as the principal element of the clinical session. Through speech and by analyzing how the subject orally communicates with others, we may listen to and discover the subject and, as the subject speaks, his relationship with another person is not restricted to a dual relationship, but rather, it includes a third party, the Other. It is the relationship between the subject and the Other that offers us a means to investigate the subject's particularities in psychosis; this is discussed through the analysis of a selected part of a clinical case.

Keywords: Subject, psychosis, language, clinical session.

A

o seguirmos os passos de Lacan quando nos convida a não recuar diante da clínica da psicose, sustentamos a hipótese da presença de sujeito nesta estrutura, sendo isto o que nos norteia em nossa escuta clínica. Como afirma Allouch (1997, p.387): "Seja com o que for que a psicanálise lide na clínica, jamais se trata de outra coisa que não de sujeito."

Inicialmente, é importante traçar um breve histórico de como Lacan introduz a noção de sujeito na psicanálise, enfatizando que ele elabora tal noção a partir de uma reflexão sobre 
o sujeito cartesiano, fundado no cogito: "penso, logo sou” e anuncia que se trata do sujeito que nasce com a ciência moderna, mas que é, entretanto, excluído pela própria ciência de seu campo de atuação (LACAN, 1965-66/1998). Tomando como fio condutor o cogito cartesiano, Lacan formula a divisão do sujeito que a experiência psicanalítica atesta com base na divisão entre saber e verdade, deixando claro que o avanço trazido pela teoria de Descartes foi fundamental para a elaboração do conceito de sujeito na psicanálise. Ao afirmar que "o sujeito sobre quem operamos em psicanálise só pode ser o sujeito da ciência” (LACAN, 1998, p.873) indica-nos que o sujeito com o qual a psicanálise lida é, por base, o sujeito da ciência, só que de forma subvertida. Ao operar a subversão do sujeito cartesiano, a partir da descoberta do inconsciente por Freud, Lacan vem demonstrar que o sujeito da psicanálise não é o sujeito da razão, mas sim algo que surge nas falhas do discurso, nos tropeços da fala. Transforma, desta maneira, a fórmula: "penso, logo sou” em "eu não sou lá onde sou joguete de meu pensamento; penso naquilo que sou lá onde não penso pensar” (LACAN, 1957/1998, p.521). Neste sentido, o sujeito da psicanálise constitui-se a partir da inserção do objeto da falta, ao contrário do sujeito cartesiano que se caracteriza como ancorado no ser.

Retomando a fórmula freudiana Wo Es war, soll Ich werden, Lacan situa o lugar do sujeito: lá onde isso estava, lá, como sujeito, devo [eu] advir. Ao incluir o objeto da falta como determinante do sujeito, o cogito só tem sentido na medida que se vincula à fala, à linguagem. O sujeito sobre o qual operamos no campo da psicanálise é o sujeito dividido, apreendido na estrutura da linguagem (LACAN, 1965-66/1998).

É nesta perspectiva que Lacan evidencia que quanto ao sujeito não se trata de um fenômeno e sim de algo que é estrutural, um sujeito marcado pela linguagem, articulado à cadeia dos significantes, sendo no ato da fala que ele pode surgir, o que fica claro quando ele se pergunta no Seminário 5: As formações do inconsciente (1957-58):

"O que é um sujeito? Será alguma coisa que se confunde, pura e simplesmente, com a realidade individual que está diante de seus olhos quando vocês dizem 0 sujeito? Ou será que, a partir do momento em que vocês o fazem falar, isso implica necessariamente uma outra coisa? (...) quando há um sujeito falante, não há como reduzir a um outro, simplesmente, a questão de suas relações como alguém que fala, mas há sempre um terceiro, o grande Outro, que é constitutivo da posição do sujeito enquanto alguém que fala.” (LACAN, 1957-58/1999, p.186)

É a partir da fala e do modo como esta é endereçada ao outro que podemos escutar e identificar o sujeito e, na medida que o sujeito é falante, sua relação 
com o outro não se fecha numa relação dual, já que inclui um terceiro, o grande Outro $^{1}$ que constitui a posição do sujeito enquanto falante. É a relação do sujeito com o Outro que nos oferece o caminho para investigar o que é específico do sujeito na psicose, o que pretendemos discutir a partir da análise de um fragmento clínico de um caso que foi atendido num Centro de Atenção Psicossocial do município do Rio de Janeiro, o Caps Clarice Lispector. É fundamental enfatizar que a idéia aqui não é fazer um estudo de caso e a partir daí empreender uma discussão teórica relacionada a ele, mas sim, justamente, utilizar um fragmento de um caso para ilustrar e clarear algumas das questões que dizemrespeito ao sujeito na estrutura clínica citada.

\section{FRAGMENTO CLÍNICO}

$\mathrm{Nara}^{2}$ é uma mulher de uns 50 anos que até dois anos atrás nunca havia realizado nenhuma forma de tratamento. Ela chegou ao Caps por ocasião de sua primeira internação, acompanhada de um sobrinho. Seus dois filhos moram em outro estado e Nara mora sozinha num apartamento da Zona Norte do Rio de Janeiro. Foi internada em virtude de um conflito com o vizinho do andar de baixo, que exigia há muito tempo que ela consertasse uma infiltração na parede. Nara, pela constante sensação de invasão que vive, recusava-se a permitir que qualquer pessoa entrasse em sua casa para resolver o problema. Deste modo, o vizinho se viu obrigado a contatar a Justiça, que enviou um oficial à casa dela, intimando-a a realizar o conserto. Encontrando-se diante de algo insuportável, Nara exaltouse e desacatou o oficial, o que resultou em prisão, seguida de encaminhamento para um manicômio judiciário. Lá, seu sobrinho, depois de muito argumentar, conseguiu que ela fosse transferida para um hospital psiquiátrico. Podemos identificar o episódio que provocou a internação de Nara como o desencadeamento de uma crise psicótica, já que a fez romper com uma organização que até então vinha dando conta de sua inserção no mundo.

Ao começar a contar o que lhe aconteceu, Nara relata a forma como se sente na relação com o Outro, indicando-nos o seu lugar de existência no mundo, lugar marcado e determinado pelo significante invasão. Há anos sente-se invadida por seus vizinhos que estão sempre a lhe usurpar tudo o que tem: namorado, trabalho, amigos. Isso se dá desde a morte do homem com quem iria se casar,

\footnotetext{
${ }^{1}$ Termo utilizado por Lacan para definir um lugar simbólico, o campo da linguagem, o tesouro dos significantes. Com essa noção, Lacan situa a questão da alteridade; o grande Outro não é o semelhante, distinguindo-se do parceiro imaginário, o pequeno outro. Foi no Seminário 2, O eu na teoria de Freud e na técnica da psicanálise (1954-1955) que introduziu pela primeira vez o termo 'grande Outro', distinguindo-o do 'pequeno outro', deixando claro que o Outro, é dele que se trata na função da fala.

${ }^{2}$ Os nomes utilizados neste artigo são fictícios para preservar a identidade dos pacientes.
} 
pois na presença dele se sentia protegida em todos os sentidos, inclusive do ponto de vista financeiro, e com sua morte tornou-se completamente vulnerável à ação deles que teve início com o boicote ao seu trabalho. Nara deixa claro que a presença deles já existia em sua vida antes, quando ainda era casada com o pai de seus filhos e morava na Bahia. Entretanto, era uma presença menos invasiva $e$ mais controlável.

Nara trabalhava como costureira em casa e tinha sua clientela. Aos poucos os clientes foram sumindo até chegar ao ponto de ela não ter mais encomendas e ficar sem dinheiro; isso se deu em paralelo à ação deles, o que a faz ter certeza do boicote a sua vida. Nesta época, começou a ter que depender dos filhos para viver, ficando muito fragilizada. Tentou ainda investir em outro trabalho, de cabeleireira em salão, ramo em que havia atuado antes, mas não deu certo, já que estava tomada e perturbada pelo boicote constante dos vizinhos. No início, tal ação manifestava-se por alguns fenômenos esquisitos que, com o tempo foram se intensificando e transformando de fato no que ocorre hoje: considera os vizinhos como pertencentes a um grupo demoníaco que age contra ela por meio do desenvolvimento de hierarquias no abstrato. É no abstrato, explica, e não por meio da realidade concreta que eles se comunicam com ela, invadindo sua mente e seu corpo. Por telepatia a fazem capaz de escutar tudo que falam e tramam. Essas falas são percebidas em seu ouvido, exercendo também uma pressão sobre sua mente e é aí que se tornam insuportáveis.

\section{ALGUMAS CONSIDERAÇÕES TEÓRICO-CLÍNICAS}

Nara sente na pele a invasão do Outro, da própria linguagem, permanecendo colada ao significante em sua literalidade. Tal condição é conseqüência da foraclusão do significante Nome-do-Pai que barra o Outro, permitindo que o sujeito se proteja de uma invasão sem piedade. É desta forma que o sujeito se apresenta neste caso, completamente exposto à ação do significante, falado e boicotado pelos fenômenos elementares (alucinações auditivas) e do automatismo mental.

"Eles me mostram as pessoas antes de eu chegar nos lugares, mostram a roupa que eu vou vestir definindo-a por mim, isso acontece principalmente quando vou a algum evento com pessoas novas, que não conheço e deste modo eles me casam via telepatia com essas pessoas que começam a agir contra mim por pressão deles.”

Neste momento, cabe esclarecer que o automatismo mental é uma síndrome definida por Clérambault, e dá conta de um conjunto de fenômenos presentes na psicose, tais como o pensamento antecipado e o eco do pensamento. Como indica Jean-Luc Ferreto (1999), o que é fundamental do automatismo mental é justamente o quanto ele é a evidência da presença invasiva do significante, do Outro, nos casos de psicose, já que diz respeito aos efeitos da marca do 
significante na relação do sujeito com o Outro. É precisamente este ponto que estamos considerando importante para a nossa reflexão sobre o lugar do sujeito na psicose.

Nara luta dia a dia para barrar o Outro e isso de fato se efetiva em parte em virtude do tratamento que lhe oferece um espaço para falar sobre tais acontecimentos. Esse lugar de escuta é fundamental para que ela organize todo o conteúdo que vem do Outro de forma massiva. Tal lugar deve ser investido de um desejo, o desejo do analista que possibilita, desta forma, a transferência com a abertura de um espaço para o sujeito, sustentando uma existência possível. O acolhimento da fala de Nara viabiliza para ela uma forma de existir que é fundamental para que possa seguir se relacionando com as pessoas de um modo a se sentir menos invadida.

É neste espaço reservado que ela se permite falar o que se passa com ela, sem medo de ser julgada ou taxada de louca. Fora deste contexto, disfarça o quanto pode o seu tormento, procurando evitar conversar com eles, pois aí iriam chamá-la de louca na rua e, louca eu não sou, diz ela. É essa abertura e a possibilidade de acolher a fala que vem do Outro, a fala delirante, da forma mais neutra possível, ou seja, de modo a não estranhá-la e julgá-la, que faz operar o desejo do analista e, por conseqüência, a transferência que se manifesta no caso de Nara pela presença semanal para compartilhar sua vivência e, desta forma, barrá-la cada vez um pouco mais. O esforço constante, diário, de Nara para barrar o Outro ilustra de forma clara o lugar do sujeito de estar à mercê de um Outro que não foi barrado, sendo nesta relação que podemos identificar o sujeito.

O estado do sujeito, tanto na neurose como na psicose, depende do que se desenrola no campo do Outro, campo da linguagem. Deste discurso o sujeito faz parte e é desta forma que ele se implica em sua existência, ou seja, é a partir do Outro que ele pode formular a questão de sua existência. Por isso estamos enfatizando a importância desta relação para pensar sobre o sujeito na psicose, um sujeito que existe como uma possibilidade que é favorecida pela escuta clínica, por meio de um endereçamento ao outro/Outro na transferência, na medida que se constrói um espaço de representação para ele. Como propõe Tenório (2001), "A idéia de que o sujeito na psicose pode (ou não) advir supõe o paradoxo de que ele está lá (a advir) e não está lá.” A proposta da clínica da psicose, neste sentido, “consiste não em fazer apelo a um sujeito que não pode responder, mas sim em criar as condições para que ali, numa existência aniquilada pela psicose, se produza essa possibilidade" (TENÓRIO, 2001, p.124).

Desta forma, é mais precisamente no que se refere à questão da existência que podemos localizar o sujeito. No caso de Nara isso fica claro quando ela define seu lugar de existência no mundo, marcado pelo significante invasão. Lacan indica que essa questão, a da existência, se coloca sob a forma de uma pergunta: "Que 
sou eu nisso?" (LACAN, 1998, p.555). Isso diz respeito ao sexo e às suas conseqüências, ser homem ou mulher e, por outro lado, diz respeito aos símbolos da procriação e da morte. Neste momento, Lacan deixa claro que a foraclusão do Nome-do-Pai diz respeito à carência não do pai real, mas sim à carência do próprio significante. Como conseqüência disto, o falo não é simbolizado para o sujeito, provocando uma ausência da significação fálica, que se manifesta por um vazio na referenciação sexual, que se nota a partir do surgimento de idéias delirantes ligadas à sexualidade e ao corpo. Nas palavras de Lacan:

“A Verwerfung será tida por nós, portanto, como foraclusão do significante. No ponto em que, veremos de que maneira, é chamado o Nome-do-Pai, pode pois responder no Outro um puro e simples furo, o qual, pela carência do efeito metafórico, provocará um furo correspondente no lugar da significação fálica." (1957-58/1998, p.564)

Ao articular o conceito de inconsciente à linguagem, Lacan enfatiza a primazia do significante sobre o significado, já que é o significante o responsável pela imposição do significado ao sujeito. O sujeito, desta forma, situa-se no intervalo significante, nas falhas do discurso, surgindo como conseqüência da operação de castração do Outro que, ao ser marcado como desejante, abre espaço para que o sujeito possa advir. Estamos nos referindo aqui ao sujeito dividido que surge como desejante. A partir do discurso de Nara, podemos dizer que o sujeito fica à mercê do Outro que faz com ele o que quer, não sendo caracterizado na perspectiva do sujeito desejante tal como foi formulado de início por Lacan. Ao tomar como referência o sujeito desejante nos remetemos a um sujeito que foi afetado, atravessado pela falta em sua relação com o Outro. Na psicose, a partir do fragmento clínico analisado, podemos pensar que a relação do sujeito com o Outro não foi atravessada pela falta, já que é uma relação não dialetizada, não mediada. A questão que surge, neste momento, é: como produzir uma mediação, uma separação, alguma forma de barrar este Outro invasivo? No caso abordado, vem sendo construída uma mediação, devagar e sutilmente, pois, à proporção que Nara se endereça ao outro, há uma tentativa de ser reconhecida por ele e isso produz algum movimento de circulação significante. Aí está o sujeito, massacrado pelo Outro, mas em vias de encontrar um novo lugar de existência.

Em sua tese de doutorado Sujeito e psicose (2000), Angela Pequeno anuncia duas versões para o sujeito que nos ajudam a pensar o modo como ele se situa na psicose. Ao realizar uma diferenciação entre o sujeito do significante e o sujeito do gozo, caracteriza o primeiro como o sujeito desejante, aquele ao qual nos referíamos no parágrafo acima. Para que ele advenha é necessário que o lugar do Outro seja marcado por uma falta, determinando-o como falta-a ser, como 
desejante. Lacan em a "Subversão do sujeito e dialética do desejo no inconsciente freudiano” (1960) define que:

"um significante é aquilo que representa o sujeito para outro significante. Esse significante, portanto, será aquele para o qual todos os outros significantes representam o sujeito: ou seja, na falta desse significante, todos os demais não representariam nada. Já que nada é representado senão para algo.” (LACAN, 1998, p.833)

É o significante Nome-do-Pai, responsável pela barra do Outro, que organiza a cadeia significante no inconsciente, fazendo a articulação entre S1 e S2. Na foraclusão desse significante, S1 não se articula a S2, o que faz com que esse primeiro significante para o qual os outros significantes representam o sujeito, fique solto, desarticulado. Como conseqüência disto, não se instaura uma falta no Outro e o sujeito fica no lugar de objeto do gozo desse Outro absoluto, não castrado. Este seria, assim, o sujeito do gozo, um sujeito que se mantém numa relação não dialetizada com o Outro, à mercê dele. Tal "versão" de sujeito indicada por Pequeno esclarece com muita propriedade em que lugar se encontra o sujeito no caso de Nara. Neste sentido, estamos apresentando uma hipótese de que o sujeito na psicose talvez possa ser caracterizado como sujeito do gozo, justamente por não ser marcado pela falta. No entanto, é importante esclarecer que tal hipótese se ancora num caso de psicose que escolhemos como referência e não pretendemos a partir dele generalizar qualquer hipótese.

No Seminário sobre O avesso da psicanálise (1969-1970) Lacan, ao deixar claro que a linguagem é a condição do inconsciente, evoca a cadeia significante para pensar quatro possibilidades de discursos: o discurso do Mestre, o discurso Universitário, o discurso da Histérica e o discurso do Analista, que organizam as posições simbólicas no laço social. Desta forma, veremos em seguida como todo discurso diz respeito ao gozo, e a relação do sujeito com o gozo refere-se a sua constituição primitiva, inaugurada a partir da operação significante que situa o sujeito no intervalo entre dois significantes. Da relação entre S1 e S2 surge o sujeito e desta operação algo resta, o objeto a, objeto causa do desejo, portanto, determinante do sujeito. Lacan afirma neste momento que a relação com o gozo "se acentua subitamente por essa função ainda virtual que se chama a função do desejo” (LACAN, 1992, p.17).

Para especificar a relação do sujeito com o Outro é importante pensar como se estabelece a relação do sujeito com o gozo. Lacan retoma Freud, numa tentativa de articular o que nele pode ser identificado ao que se caracteriza como gozo. Ao fundar a noção de inconsciente, Freud nos permite situar o desejo. Em "Além do princípio do prazer" (1920), menciona a questão da repetição para definir a pulsão de morte. Lacan privilegia este texto para mostrar a articulação entre 
pulsão de morte e gozo, por meio do conceito de repetição, ao afirmar que é o gozo que necessita da repetição. Em suas palavras:

Na medida em que há busca do gozo como repetição que se produz o que está em jogo no franqueamento freudiano o que nos interessa como repetição, e se inscreve em uma dialética do gozo, é propriamente aquilo que se dirige contra a vida. É no nível da repetição que Freud se vê de algum modo obrigado, pela própria estrutura do discurso, a articular o instinto de morte. (LACAN, 1969-70/1992, p.43)

A repetição define um ciclo que busca o retorno ao inanimado, e é neste ponto que podemos fazer uma ligação com o gozo tal como descrito por Lacan, indicando que, na produção da linguagem há uma perda de gozo, e a repetição seria uma tentativa de recuperar este gozo perdido. Porém, como Freud afirma, o próprio processo de repetição implica uma perda na qual se origina, no discurso freudiano, a função do objeto perdido. É no lugar dessa perda, introduzida pela repetição, que Lacan situa o que chama de objeto $a$, sendo por meio deste que o gozo se introduz na dimensão do ser do sujeito. Portanto, o que diz respeito ao gozo está diretamente ligado à falta que circunscreve o desejo, como nos diz Lacan, “(...) esse ponto de perda, é o único ponto, o único ponto regular por onde temos acesso ao que está em jogo no gozo. Nisto se traduz, se arremata e se motiva o que pertence à incidência do significante no destino do ser falante" (LACAN, 1969-70/1992, p.49). Desta forma, não há discurso que não seja discurso do gozo e, se o que aponta para o gozo está ligado à falta, podemos arriscar a dizer que se trata aí do discurso da falta.

E na psicose, como se dá a relação do sujeito com o gozo? Ao nos determos no caso de Nara, observamos que em sua relação singular com a linguagem ela, ao falar, esboça a fala do Outro, mostrando-se atada à experiência invasiva vivida em sua relação com o abstrato — o abstrato é o Outro, a própria linguagem. O gozo aparece aí não delimitado pela falta e, portanto, invasivo para o sujeito.

A relação do sujeito na psicose com a linguagem se dá de um modo em que ele não se insere ou não é inserido no que chamaríamos de discurso, ou seja, o sujeito está na linguagem, mas não está no discurso. E o que é estar no discurso? É estar numa relação dialetizável, de troca com o Outro e não subsumido ao Outro. Neste sentido, o sujeito, ao falar, esboça uma fala que não é compartilhada socialmente, colocando-se à margem do que poderíamos chamar de laço social.

No Seminário sobre As psicoses (1955-56), ao teorizar a respeito da psicose, Lacan considera os fenômenos que ocorrem nesta estrutura clínica como fenômenos de linguagem, enfatizando que a psicose provém de algo que se situa nas relações do sujeito com o significante. Há uma relação especial do psicótico com a linguagem que determina o sujeito. O psicótico é um testemunho aberto do 
inconsciente e a psicanálise, neste sentido, legitima o discurso delirante como discurso do inconsciente, por ele estar amarrado ao significante na sua mais pura literalidade.

O acesso do psicótico ao simbólico é, deste modo, singular, o que não significa, contudo, que ele esteja excluído de tal registro, pois este preexiste ao sujeito. Lacan explica que o psicótico fica no lugar de testemunha aberta do inconsciente, do discurso do Outro, por ele não ter o véu do recalque que protege o neurótico em sua relação com o Outro, definindo um lugar para ele de ser gozado pelo Outro incessantemente. A passagem supracitada sobre o sujeito no Seminário 5 (1957-1958), indica com muita clareza que, quando falamos, nos remetemos a um outro (semelhante) e, por meio desta relação, nos remetemos ao Outro. Na psicose, por não haver uma mediação simbólica, o outro é tomado como Outro absoluto que invade e ordena. Acredito ser neste sentido que Pequeno (2000) caracteriza o sujeito da psicose como sendo o sujeito do gozo e não do significante.

Retomando o início deste artigo, consideramos que, no exercício da clínica da psicose, aposta-se na existência do sujeito, um sujeito que se organiza com bases em uma estruturação específica, e que marca sua diferença em relação à neurose, por exemplo. Todavia, por que estamos sempre a comparar a psicose com a neurose? Isso parece facilitar a abordagem da psicose, mas, ao contrário, pode também dificultar sua apreensão, na medida que corremos o risco de pensar a clínica da psicose tendo como parâmetro a clínica da neurose, o que seria, no mínimo, precoce. Freud, ao não reconhecer a especificidade da transferência psicótica, considera o estudo psicanalítico das neuroses uma condição para a abordagem das psicoses e, abordar as psicoses a partir das neuroses significa construir um muro quase intransponível, com relação ao qual psicanálise e psicose não se encontram do mesmo lado. Pensar a transferência psicótica com base na teoria freudiana nos faz partir de um falso suposto, pois Freud teorizou o conceito de transferência a partir de sua escuta da neurose e não cabe adaptálo para a psicose, pois esta é marcada por outra lógica, por outra organização. Pensar a clínica da psicose significa considerá-la independente da neurose e de seus pressupostos. Neste sentido, Lacan, apesar de seu retorno a Freud, não foi seu prolongador, pois, ao desenvolver a clínica das psicoses e afirmar a incidência da transferência na mesma, teve que partir de outro paradigma, para além de Freud.

No Seminário sobre As psicoses (1955-56), ao especificar a relação particular do psicótico com a linguagem, Lacan enfatiza que “(...) convém escutar aquele que fala, quando se trata de uma mensagem que não provém de um sujeito para-além da linguagem, mas de uma fala para-além do sujeito" (LACAN, 1957-58/1998, p.581). Identificamos o sujeito pelo modo como constrói e como dirige sua fala 
ao outro, seja pelo delírio ou por uma posição de apagamento que muitas vezes aparece nos casos de psicose. Nesta perspectiva, no Seminário sobre Le Sinthome (1975-76), Lacan se refere à condição parasita da palavra, da linguagem, quando analisa a presença de palavras impostas no caso de Joyce. Ele assinala que todo ser humano, ou seja, todo ser que está mergulhado na linguagem, é, de certa forma, vítima da condição parasitária da palavra. Entretanto, diz: “A questão é mais de saber por que é que um homem normal, dito normal não percebe que a palavra é um parasita? Que a palavra é uma cobertura. Que a palavra é a forma de câncer pela qual o ser humano é afetado" (LACAN, 2005, p.95).

Esta afirmação nos coloca diante da diferença que marca a relação do sujeito na psicose com a linguagem, encontrando-se no lugar de refém de sua condição parasitária, invadido por ela, manipulado por ela. Neste sentido, observamos que a palavra é colocada na relação com o sujeito psicótico como lhe sendo exterior, vinda de fora e não de dentro, o que significa não se apropriar, não ter o domínio da linguagem, ou pelo menos a ilusão de ter tal domínio. Todos os seres humanos, seres de linguagem, são dominados, de certa forma, por ela, no entanto, alguns, os ditos normais, têm a ilusão de que a dominam e isso, por ser um dado da estrutura, parece ser suficiente para protegê-los da condição parasitária da linguagem.

Para refletirmos sobre a forma como, na psicose, o sujeito se dirige ao outro/ Outro, é importante lembrarmos como Schreber se endereçou a seu médico, o Dr. Flechsig, o que vem atestar a relação transferencial que se deu entre os dois. Foi ele quem atendeu Schreber por ocasião de sua primeira doença, um período anterior à instalação de sua crise. Nesse momento ele obteve certo sucesso no tratamento, ganhando a afeição por parte de Schreber e de sua esposa. Mais à frente, num tempo posterior, quando de fato a crise delirante se instalou, o médico mudou de lugar, havendo uma inversão: ao invés de ser objeto da afeição virou objeto do ódio. Esta inversão, segundo Freud, teria relação com o impulso homossexual que estaria na base da paranóia, o que vai ser questionado por Lacan. Dr. Flechsig ganha assim o lugar de perseguidor que exerce forte influência sobre Schreber.

No entanto, é à Flechsig que Schreber se endereça por meio do pedido para que realize um exame benévolo de seus escritos, suas memórias. Flechsig ganha um lugar na transferência - lugar que fica evidente na carta aberta escrita para ele - lugar de destinatário. Pede desculpas pelas coisas que escreveu sobre ele; no entanto, as reforça, atestando sua posição delirante ao evidenciar a real influência emanada do sistema nervoso de Flechsig sobre o seu sistema nervoso. Afirma com toda certeza que mesmo à distância Flechsig manteve com seus nervos uma relação hipnótica e sugestiva. O que é interessante pontuarmos aqui é a importância do endereçamento do discurso delirante ao outro como tendo 
função de estabilização para o sujeito que encontra espaço para se representar. Para que isso efetivamente se dê é preciso que o discurso delirante seja acolhido pelo destinatário para que de fato ganhe um sentido de estabilização e não se transforme em puras letras sem sentido.

O discurso delirante de Schreber foi endereçado ao outro, numa tentativa de ser reconhecido pelo Outro, aquele ao qual nos dirigimos para além do semelhante, do outro imaginário. Como ele demonstra pelo "sistema do nãofalar-até-o-fim" (SCHREBER, 1985, p.209), a interrupção da mensagem aponta para um abandono ao qual o psicótico está sujeito, não sendo reconhecido pelo Outro. A articulação delirante de Schreber indica que não ter o reconhecimento do Outro faz com que o sujeito seja constantemente invadido por uma "coação a pensar", por frases interrompidas e desconexas. Neste sentido, ao ser acolhido pelo destinatário, que pode ser o psicanalista, o discurso delirante tem possibilidade de ganhar um sentido de ancoramento e de organização para o sujeito.

O trabalho clínico com a psicose, desta forma, deve caminhar na direção de acolher ou até produzir um possível endereçamento, criando condições para que o sujeito, que muitas vezes parece não estar lá, possa encontrar um espaço de existência. Para que isto seja possível, é preciso acompanhar o psicótico na criação de meios para barrar o Outro, sendo este trabalho o que Lacan chamou de secretariar, quando nos aconselhou a ser secretários do alienado. No caso de Nara isto se produz a cada dia por meio de um acolhimento de sua produção delirante, o que tem lhe possibilitado um lugar de existência menos invadido e, portanto, menos sofrido.

Este lugar de escuta sustentado pelo psicanalista deve seguir parâmetros diferentes dos adotados no caso da clínica com a neurose. Isso é fundamental se quisermos realmente pensar em uma clínica da psicose. Como indica Zenoni (2000), invertendo os termos da equação freudiana, ao invés de se aplicar a psicanálise com neuróticos à psicose, o que resulta infrutífero, aplica-se a psicose à psicanálise, pois a própria psicose nos ensina sobre sua estrutura, sua lógica, indicando-nos o caminho de escuta que devemos seguir, por meio das soluções que ela mesma encontra para lidar com a falta estrutural do significante paterno. Neste ponto, esvazia-se o sujeito suposto saber, base da transferência no tratamento psicanalítico com neuróticos, pois quanto mais esvaziado é esse sujeito do saber, mais se torna possível a clínica. Em suas palavras: “É na escola da psicose que nós nos colocamos para aprender como praticar” (ZENONI, 2000, p.19).

Ao reenviarmos a noção de "sujeito suposto saber” à clínica da psicose, observamos que tal noção ganha um sentido mais nítido a partir da reflexão do que ocorre nas psicoses, como fica claro na leitura que Allouch (1997) faz da tese de doutorado de Lacan: 
“De fato, é nas psicoses que se encontra, muito mais ostensivamente que em outros lugares, a posição de um Outro suposto saber e talvez da maneira mais pura no delírio de suposição, onde o sujeito crê saber que o Outro sabe, sem mesmo às vezes jamais ter necessidade de saber, de inventar aquilo que o Outro sabe (...)" (ALLOUCH, 1997, p.440)

Esse Outro, contudo, é absoluto, e o saber é tomado como certeza. É pela crença presente no delírio de que o Outro sabe e, portanto, invade o sujeito, que a posição do psicanalista como sujeito-suposto-saber deve ser repensada na direção clínica do trabalho com o psicótico. Quem porta um saber aí é o sujeito, já que ele tem certeza de que o Outro sabe sobre sua vida, sobre seus pensamentos, sobre a sua condição e, neste sentido, o persegue, o tortura, o faz refém, prisioneiro. A regra no campo paranóico das psicoses é o saber como sendo inicialmente o saber do Outro, e é a partir desse registro que a especificidade da transferência aí se apresenta, marcada por uma estrutura ternária: o psicótico fala ao psicanalista algo que lhe é falado pelo Outro. O psicanalista não tem aí outra escolha a não ser afirmar, em seu diálogo com o alienado, a posição do alienado de testemunha, de narrador do que lhe vem do Outro, exercendo a função de secretário. Mas, o que vem a ser testemunha do discurso do Outro? Como diz Lacan, no Seminário sobre As psicoses (1955-56):

“(...) o psicótico é um mártir do inconsciente, dando ao termo mártir seu sentido, que é o de testemunhar. Trata-se de um testemunho aberto. O neurótico também é uma testemunha da existência do inconsciente, ele dá um testemunho encoberto, que é preciso decifrar. O psicótico, no sentido de que ele é, numa primeira aproximação, testemunha aberta, parece fixado, imobilizado, numa posição que o coloca sem condições de restaurar autenticamente o sentido do que ele testemunha, e de partilhá-lo no discurso dos outros.” (LACAN, 1955-56/1985, p.153)

O psicanalista, ao ocupar o lugar de secretário, para além de afirmar a posição do sujeito de testemunha aberta do discurso do Outro, pode ajudá-lo a construir um sentido para isto que ele testemunha. Assim, seu papel é ativo, o que significa não apenas registrar o que a testemunha relata, mas tomar seu testemunho "ao pé da letra".

Tal assertiva nos leva a refletir ainda mais sobre a vivência desta clínica que é marcada por surpresas e que exige assim certa dose de criatividade e jogo de cintura nas intervenções necessárias para cada situação. Ao nos abrirmos para um novo aprendizado clínico, a partir do que a própria estrutura psicótica nos ensina, vamos, aos poucos, construindo formas de pensar esse trabalho. O lugar de aprendiz é fundamental, por abrir caminhos de intervenções clínicas guiadas 
pelo sujeito que vai ensinando o que ele pode e o que não pode suportar. Trata-se de algo difícil, já que temos que nos desviar o tempo todo de um lugar de quem sabe para irmos ao encontro de um sujeito frágil que pode se sentir invadido muito facilmente, fechando portas para um trabalho possível.

O esvaziamento do saber prévio propicia o surgimento de um lugar para o psicanalista de sujeito suposto não saber que é, como indica Zenoni:

"uma posição favorável para encontrar um sujeito que sabe o que acontece com ele, que é ele mesmo a significação do que lhe é endereçado enigmaticamente. É uma posição favorável para encontrar esse sujeito, sem alimentar uma posição intensiva, persecutória de transferência. (...) Na psicose o saber não é suposto, mas realizado pelo próprio sujeito, que é a referência, o gozo desse saber. É por isso que quando o Outro se apresenta como o Outro do saber, ele pode ser encontrado sob uma forma erotomaníaca ou persecutória. Enquanto que a posição do sujeito não saber deixa principalmente ao sujeito a iniciativa de saber.” (2000, p.20)

Podemos identificar isso no caso de Nara que construiu uma realidade delirante para explicar e dar algum sentido a sua vivência psicótica. Seus vizinhos são os responsáveis por tudo o que acontece de ruim a ela, pois eles invadem seus pensamentos, lendo-os, dando-lhe ordens imperativas, exigindo que ela deite com eles e usando seu corpo, sua "fachada" para conseguirem as coisas, como drogas, por exemplo. Obrigam-na a assinar procurações que lhes dão plenos poderes, já que ela é uma superintendente de assuntos gerais do mundo, do universo, uma pessoa muito importante. Tais pessoas têm um poder especial, agindo de forma velada, aparecendo somente para ela, promovendo dores em seu corpo, mal-estares. Essa forma que Nara criou para ordenar, organizar e entender o que se passa com ela é a própria realidade delirante.

Ao escutar o discurso de Nara, percebe-se que ele é marcado por uma certeza e por um saber que não devem ser contestados, e o acolhimento destes viabiliza a transferência e a possibilidade de Nara se proteger. Dando ênfase à formulação de Lacan sobre a relação particular do sujeito na psicose com o significante, relação esta que faz com que o sujeito compareça aí como sujeito do gozo na medida que está à mercê do Outro, da própria linguagem, é a escuta se pautando por essa referência, no caso de Nara, pelo saber delirante, que nos conduzirá à construção da clínica. O saber do sujeito, aliado a um não saber do psicanalista e da equipe, pode ser considerado, assim, o responsável pela realização da clínica da psicose. 


\section{REFERÊNCIĀS}

ALLOUCH, J. (1997) Marguerite ou a "Aimée" de Lacan. Rio de Janeiro: Companhia de Freud.

FERRETO, J-L. (2004) O automatismo mental. Revista Tempo Freudiano, v. 1, n. 3. A clínica da psicose: Lacan e a psiquiatria — os fenômenos elementares. Rio de Janeiro: Tempo Freudiano Associação Psicanalítica, p. 95-115.

LACAN, J. (1954-55/1985) O Seminário livro 2, O eu na teoria de Freud e na técnica da psicanálise. Rio de Janeiro: Jorge Zahar.

(1955-56/1985) O Seminário livro 3, As psicoses. Rio de Janeiro: Jorge Zahar.

(1957/1998) "A instância da letra no inconsciente ou a razão desde Freud”, in Escritos. Rio de Janeiro: Jorge Zahar.

(1957-58/1998) "De uma questão preliminar a todo tratamento possível da psicose", in Escritos. Rio de Janeiro: Jorge Zahar.

. (1957-58/1998) O Seminário livro 5, As formações do inconsciente. Rio de Janeiro: Jorge Zahar.

(1965-66/1998) "A ciência e a verdade", in Escritos. Rio de Janeiro: Jorge Zahar.

(1969-70/1992) O Seminário livro 17, O avesso da psicanálise. Rio de Janeiro: Jorge zahar.

(1975-76/2005) O Seminário livro 23, Le Sinthome. Paris: Éditions du Seuil.

PEQUENO, A. (2000) "Sujeito e psicose”. Tese de doutorado, Programa de Pós-graduação em Psiquiatria e Saúde Mental (Propsam), Instituto de Psiquiatria, Universidade Federal do Rio de Janeiro.

ZENONI, A. (2000) Psicanálise e Instituição: A segunda clínica de Lacan. Abrecampos. Revista de Saúde Mental do Instituto Raul Soares, ano I, n. 0. Belo Horizonte: Rede Fhemig, p. 9-70.

Gabriela Rinaldi Meyer

gabide@uol.com.br 